\title{
Clinical Performance of CAD/CAM Tooth-Supported Ceramic Restorations: A Systematic Review
}

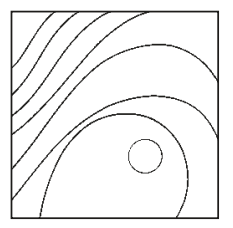

Inês Filipa Alves de Carvalho, DMD 1

Tiago Miguel Santos Marques, DMD²

Filipe Miguel Araújo, DMD²

Luís Filipe Azevedo, MD, $P h D^{3}$

Helena Donato, $\mathrm{MLS}^{4} /$ André Correia, DMD, $\mathrm{PhD}^{5}$

Owing to an increased demand for safe and esthetically pleasing dental materials, ceramics have been developed and optimized to rehabilitate anterior and posterior teeth. This evolution in ceramic materials is directly related to the development of sophisticated processing technologies and systems for use in dental medicine, particularly computer-aided design/computer-assisted manufacture (CAD/CAM) technology. This study is a systematic review outlining long-term clinical survival rates of single-tooth restorations fabricated with CAD/CAM technology with a minimum follow-up of 3 years. A bibliographic search up to September 2016 was performed using two databases: MEDLINE (PubMed) and Embase. Selected keywords and well-defined inclusion and exclusion criteria guided the search of relevant results. All articles were first reviewed by title, then by abstract, and subsequently by a full text reading. Data were assessed and extracted through a standardized form. The pooled results were statistically analyzed, and the overall failure rate was calculated by random effects model. Reported failures were analyzed by CAD/CAM system, type of restoration, restorative material, and luting agent. From a total of 2,916 single-tooth restorations with a mean exposure time of 7.0 years and 351 failures, the failure rate was $2.17 \%$ per year, estimated per 100 restoration years ( $95 \%$ confidence interval [Cl]: $1.35 \%$ to 3.51\%). The estimated total survival rate after 5 years was $89.7 \%$ (95\% Cl: $88.1 \%$ to $91.1 \%$ ). The overall survival rate of single-tooth ceramic restorations fabricated with CAD/CAM technology was similar to those conventionally manufactured. Int J Periodontics Restorative Dent 2018;38:e68-e78. doi: 10.11607/prd.3519

${ }^{1}$ Instructor, Universidade Católica Portuguesa, Institute of Health Sciences of Viseu, Viseu, Portugal.

'Lecturer, Universidade Católica Portuguesa, Institute of Health Sciences of Viseu, Viseu, Portugal.

${ }^{3}$ Assistant Professor, University of Porto, Faculty of Medicine, Family Medicine Unit, Social Sciences and Health Department, Porto, Portugal; University of Porto, Faculty of Medicine, Center for Research in Health Technologies and Information Systems (CINTESIS) and Information Sciences and Decision on Health Department (CIDES), Porto, Portugal.

${ }^{4}$ Director, Coimbra Hospital and University Centre, Documentation Department,

Coimbra, Portugal.

${ }^{5}$ Assistant Professor, Universidade Católica Portuguesa, Institute of Health Sciences of Viseu, Viseu, Portugal; Universidade Católica Portuguesa, Centro de Investigação Interdisciplinar em Saúde (CIIS), Viseu, Portugal; Universidade do Porto Instituto de Engenharia Mecânica e Gestão Industrial, Laboratório de Óptica e Mecânica Experimental, Porto, Portugal.

Correspondence to: Dr I. Carvalho, Universidade Católica Portuguesa, Institute of Health Sciences of Viseu, Estrada da Circunvalação, Viseu, Viseu, Portugal 3504-505.

Fax: +351 232428 344. Email: ines.f.a.c@gmail.com

C)2018 by Quintessence Publishing Co Inc.
Increased concern with dental esthetics prompted the development of ceramic materials that were mechanically suitable for the rehabilitation of anterior and posterior teeth and capable of mimicking the natural dental structure.1,2 Laboratory use of these materials has followed the evolution of the technologies used to process them. Although some ceramics can still be applied in a traditional way, most are now processed with CAD/CAM technology. ${ }^{1}$ The CAD/CAM systems made it possible to standardize the quality of materials, reduce production costs, and standardize the manufacturing process. ${ }^{3}$

The introduction of such technology into clinical practice should ideally be based on scientific evidence. However, evidence-based data obtained from well-controlled investigations is rarely available. The systematic review of the available literature proposed in this paper sought to establish a starting point for reconciling current viewpoints regarding clinical survival rates of single-tooth restorations fabricated with CAD/CAM technology following more than 3 years of functional service.

\section{Materials and Methods}

This systematic review was conducted following the preferred report- 


\section{Table 1 MEDLINE (PubMed) and Embase Search Strategy and Filters Applied}

\section{MEDLINE (PubMed)}

Processing technology

Type of indirect restoration

"Computer-aided design" [MeSH] OR "computer aided

manufacturing" OR "CAD CAM" OR "computer dentistry" OR

"computer milled prosthesis" OR "Cerec"

Filters

Humans, observational study, research support, multicenter study,

randomized controlled trial, evaluation studies, controlled clinical trial,

comparative study, clinical trial

\section{Embase}

Processing technology

Type of indirect restoration

"Computer-aided design" OR "Computer aided manufacturing" OR

"CAD" AND "CAM" OR "computer" AND "dentistry" OR

"computer" AND "milled" AND "prosthesis" OR "Cerec"

AND "Crowns" [MeSH] OR

"inlays" [MeSH]

Filters

Humans, longitudinal study, prospective study, retrospective study, randomized controlled trial, controlled study, controlled clinical trial, comparative study, clinical trial

ing items for systematic reviews and meta-analyses (PRISMA) statement ${ }^{4}$ and the patient, intervention, comparison, outcomes (PICO) method $^{5}$ as applicable in relation to the topic of the review:

- Patient: Adults

- Intervention: CAD/CAM singletooth ceramic restorations

- Comparison: Conventional ceramic restorations

- Outcomes: Long-term survival rates

- Focused Question: What is the long-term survival rate obtained by CAD/CAM single-tooth restorations compared to conventional ceramic restorations in an adult population with a minimum follow-up of 3 years?
Information Sources and

Data Extraction

An electronic search of publications was performed in two electronic databases, MEDLINE (PubMed) and Embase Library, with a platformspecific search strategy consisting of combinations of controlled terms (MeSH/EMTREE) and text words. Restrictions regarding the type of study and target population were applied (Table 1). In addition, a manual search was conducted to screen the references of the included publications for relevant articles. Two reviewers (I.C., T.M) independently conducted the manual search, and any disagreement was resolved by consensus.

\section{Screening Process}

The search strategy used for MEDLINE (PubMed) was a combination of $\mathrm{MeSH}$ and text words, and the search strategy used for Embase was a combination of EMTREE and text words. Filters regarding the type of study and target population were applied on both electronic databases (Table 1).

The search was performed on September 22, 2016. There was no lower limit for the analyzed time frame. All data from both electronic databases were collected, and duplicates were deleted.

In addition, the references of the selected articles were reviewed for possible inclusion. This search strategy is outlined in Fig 1. The titles and abstracts of all articles 


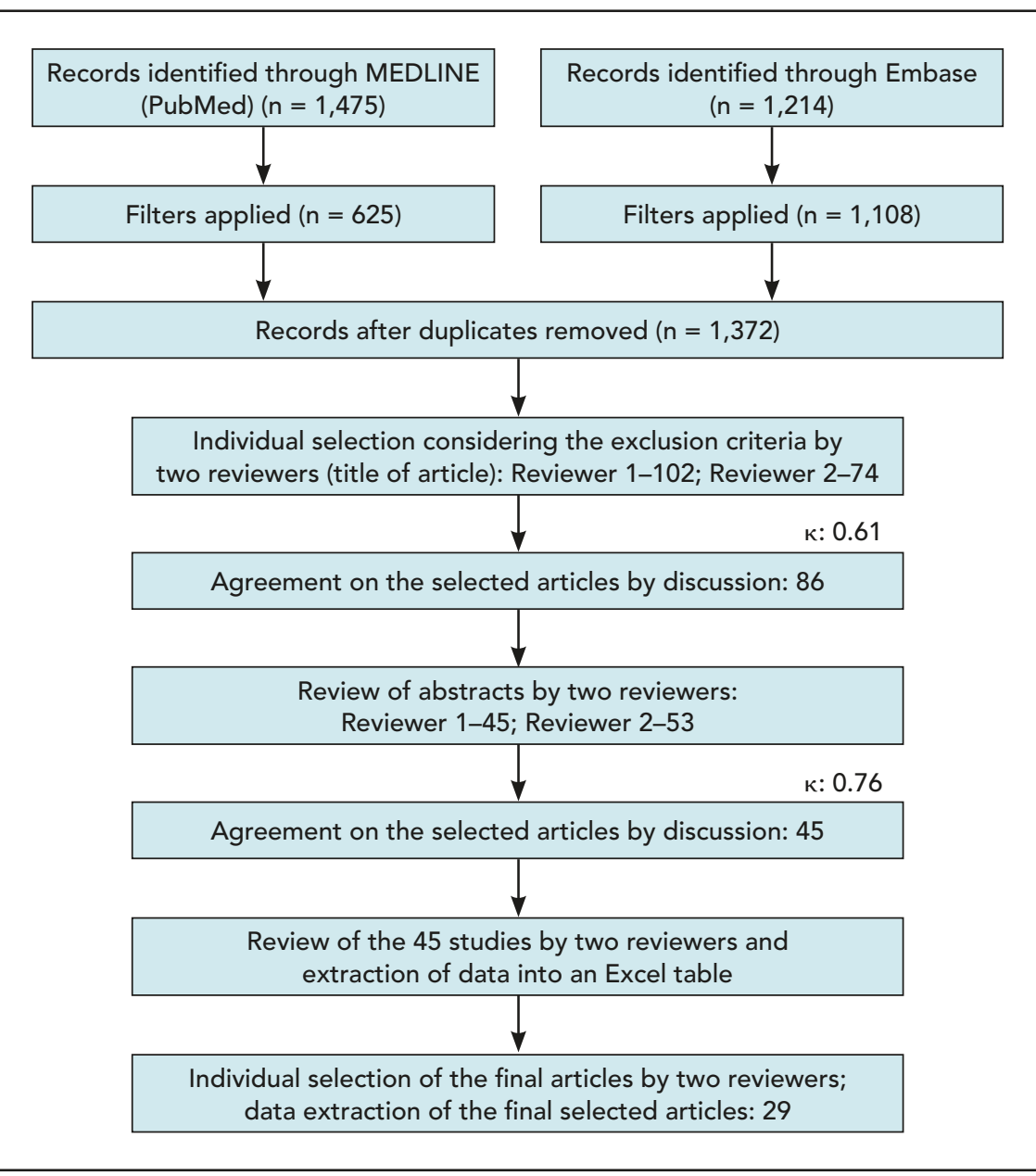

Fig 1 Search design and strategy.

\section{Table 2 Inclusion and Exclusion Criteria}

\section{Inclusion criteria}

Written in English

In vivo study

Minimum follow-up of $3 y$

Subjects were adults aged $\geq 18 y$

\section{Exclusion criteria}

Not written in English

Minimum follow-up $<3$ y

Based on patients' charts

Based on questionnaires

Case reports

Animal studies

In vitro studies were reread and identified for possible inclusion by two independent reviewers. Reviewer agreement was statistically evaluated through Cohen's kappa test. Next, the full text

\section{Study Classification}

The data for each individual restoration were extracted from the selected studies and recorded on an Excel spreadsheet. The spreadsheets were organized by author, year, type of study (prospective/retrospective/randomized controlled trial $[R C T])$, restoration type, tooth location (anterior/posterior), CAD/ CAM system, survival time (in years), restoration material, luting cement, and failure (yes/no). The restorations were categorized as core crown, crown, inlay/onlay, endo crown, reduced crown, and veneer.

\section{Statistical Analysis}

The effect size (failure rate) was defined in this study by dividing the number of events (failures) by the total time in function (years). The number of failures was extracted directly from the publications, while the total exposure time was calculated by multiplying the number of restorations by the mean exposure time in years. For each failure rate (estimated per 100 restoration years) the $95 \%$ confidence interval (Cl) was calculated assuming a Poisson distribution.

After normalizing the data, it was possible to compare studies. Because the number of patients and thus the number of restorations varies from study to study, the size of the effect depends on the size of the sample. This difference can be overcome by assigning a weight to each study; in other words, the variability of the studies is weighted. 
Cochran $\mathrm{Q}$ test was performed $(P<.001 ; 95 \% \mathrm{Cl})$ to assess the heterogeneity among the selected studies. The presence of heterogeneity was analyzed through the inconsistency test $\left(1^{2} \geq 50 \%\right)$. Since heterogeneity was $>50 \%\left(\mathrm{Q}\right.$ test and $\mathrm{l}^{2}$ ), it was not possible to apply a fixed effects model. As a result, it could not be considered that all studies came from the same population and that there was homogeneity between them. Thus, the overall failure and the weight assigned to each study were determined using the random effects model. The 5 -year survival rates were calculated for all parameters by the ratio of the event rate and the function $S: S(t)=\exp (-t \times$ event rate).

Failure rates of CAD/CAM systems (commercial brands), restoration type (core crown, crown, inlay/ onlay, endo crown, reduced crown, veneer), restoration material (glassmatrix ceramic, polycrystalline ceramic, resin-matrix ceramic), and luting cement (chemically, light-, or dual-cured) were estimated by random effects model.

Five-year survival rates were calculated for all factors as the relationship between event rate and survival function $S, S(t)=\exp (-t \times$ event rate), assuming constant event rates were given. For each five-year survival rate, $95 \% \mathrm{Cls}$ were calculated. To constrain $\mathrm{S}(\mathrm{t})^{\prime}$ 's confidence intervals to lie within the interval $(0,1)$, they were calculated in a log scale $[\mathrm{V}(\mathrm{t})]$ (complementary log-log transform [CLL]), and posteriorly the inverse transformation was applied:

$$
\begin{gathered}
S(t)=e^{-e^{V(t)}}, 95 \% \mathrm{Cl}: \\
\left.\left.\left[e^{-e^{V(t)+2 S E}} C L L^{(t)}\right), e^{-e^{V(t)-2 S E}} C L L^{(t)}\right)\right]
\end{gathered}
$$

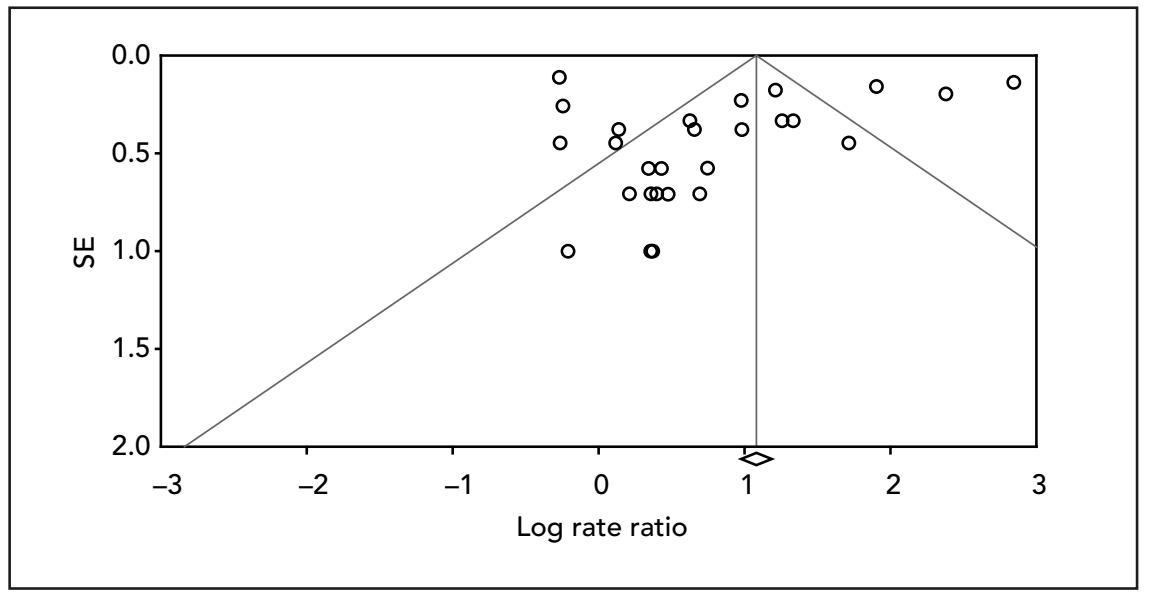

Fig 2 Funnel plot of standard error (SE) by log rate ratio.

The statistical analyses were performed using Comprehensive Meta-Analysis (Biostat), and the significance level was set at 05 .

The risk of publications bias for this meta-analysis was evaluated through a funnel plot (Fig 2). Although the funnel plot appears to be asymmetrical, through Begg and Mazumdar rank correlation it is not possible to conclude the existence of asymmetry $(P=.34)$.

\section{Results}

The initial search using the terms mentioned in the previous section led to 1,372 articles (MEDLINE [PubMed] [n = 625]; Embase [n = 1,108]; duplicates excluded $[n=361])$. After applying the exclusion criteria mentioned above, a total of 29 articles ${ }^{6-34}$ representing 23 prospective studies, 3 RCTs, and 3 retrospective studies were selected for data analysis with $\kappa$ agreement scores of 0.61 for titles and 0.76 for abstracts. The total of 2,916 restorations included $52 \%$ that were prospectively analyzed, 42\% that were studied retrospectively, and $5 \%$ that were analyzed in RCTs. The majority of the studied restorations (88\%) were on posterior teeth (premolars and molars), while only $3 \%$ were on anterior teeth. For a high percentage $(9 \%)$ of restorations, no information was given in the article on the location of the teeth (Table 3). Table 4 presents an overview of the included studies and restorations, the mean exposure time in years, $P$ values, and estimated failure and survival rates for each CAD/CAM system, different type of restoration, material, and luting agent used in the selected studies.

The 2,916 restorations analyzed revealed a mean exposure time of 7.0 years. A total of 351 failures occurred, resulting in an overall survival rate of $87.5 \%$ after 5 years $(95 \%$ Cl: $84.5 \%$ to $90.0 \%)$. This represents a calculated failure rate of $2.17 \%$ per year, estimated per 100 restoration years (95\% Cl: $1.35 \%$ to $3.51 \%)$. The failure rates per study are presented in Table 3 and Fig 3, in which the weight of each of the selected studies is listed as well. 
Table 3 Descriptive and Failure Analysis: Overview of Exposure Time, Study Type, Location, and Failure Rate of Included Studies

\begin{tabular}{|c|c|c|c|c|c|c|c|}
\hline Study & $\begin{array}{l}\text { Restorations } \\
\text { (n) }\end{array}$ & $\begin{array}{c}\text { Total } \\
\text { exposure } \\
\text { time (y) }\end{array}$ & Study type & $\begin{array}{l}\text { Tooth } \\
\text { location }\end{array}$ & $\begin{array}{l}\text { Mean } \\
\text { exposure } \\
\text { time }(y)\end{array}$ & $\begin{array}{c}\text { Failures } \\
(\mathrm{n})\end{array}$ & $\begin{array}{c}\text { Estimated failure rate } \\
\text { (per } 100 \text { restoration y) } \\
(\%[C I])\end{array}$ \\
\hline Isenberg et al ${ }^{6}$ & 121 & 363 & Pro & Posterior & 3 & 7 & $1.93(0.92-4.04)$ \\
\hline Heymann et $\mathrm{al}^{7}$ & 42 & 154 & Pro & Posterior & 3.7 & 0 & - \\
\hline Thordrup et al ${ }^{8}$ & 30 & 90 & Pro & Posterior & 3 & 5 & $5.56(2.31-13.35)$ \\
\hline Molin and Karlsson? & 20 & 100 & Pro & Posterior & 5 & 2 & $2.00(0.50-8.00)$ \\
\hline $\begin{array}{l}\text { Pallesen and van } \\
\text { Dijken }{ }^{10}\end{array}$ & 32 & 256 & Pro & Posterior & 8 & 9 & $3.52(1.83-6.76)$ \\
\hline Reiss and Walther ${ }^{11}$ & 1,010 & 10,605 & Retro & Posterior & 10.5 & 81 & $0.76(0.61-0.95)$ \\
\hline Thordrup et al ${ }^{12}$ & 14 & 70 & Pro & Posterior & 5 & 1 & $1.43(0.20-10.15)$ \\
\hline Otto and De Nisco ${ }^{13}$ & 187 & 1,917 & Pro & Posterior & 10.3 & 15 & $0.78(0.47-1.30)$ \\
\hline Bindl and Mörmannn ${ }^{14}$ & 43 & 140 & Pro & Posterior & 3.3 & 2 & $1.43(0.36-5.72)$ \\
\hline Reich et al ${ }^{15}$ & 54 & 162 & Pro & $\begin{array}{l}\text { Anterior } \\
\text { and posterior }\end{array}$ & 3 & 2 & $1.24(0.31-4.94)$ \\
\hline Sjögren et al ${ }^{16}$ & 61 & 610 & Pro & Posterior & 10 & 7 & $1.15(0.55-2.41)$ \\
\hline Bindl and Mörmann ${ }^{17}$ & 36 & 134 & Pro & Anterior & 3.7 & 2 & $1.49(0.37-5.96)$ \\
\hline Fasbinder et al ${ }^{18}$ & 71 & 213 & Pro & Posterior & 3 & 3 & $1.41(0.45-4.37)$ \\
\hline Bindl et al ${ }^{19}$ & 208 & 953 & Pro & Posterior & 4.6 & 32 & $3.36(2.38-4.75)$ \\
\hline Thordrup et a|20 & 15 & 143 & Pro & Posterior & 9.5 & 3 & $2.11(0.68-6.50)$ \\
\hline Guess et $a^{21}$ & 23 & 69 & Pro & Posterior & 3 & 1 & $1.45(0.20-10.29)$ \\
\hline Kokubo et al 22 & 75 & 482 & Pro & $\begin{array}{l}\text { Anterior } \\
\text { and posterior }\end{array}$ & 6.4 & 9 & $1.87(0.97-3.59)$ \\
\hline Beuer et $a^{23}$ & 50 & 146 & Pro & $\begin{array}{l}\text { Anterior } \\
\text { and posterior }\end{array}$ & 2.9 & 0 & - \\
\hline Vanoorbeek et al ${ }^{24}$ & 85 & 237 & Pro & $\begin{array}{l}\text { Anterior } \\
\text { and posterior }\end{array}$ & 2.8 & 9 & $3.80(1.97-7.29)$ \\
\hline Federlin et al ${ }^{25}$ & 23 & 124 & Pro & Posterior & 5.4 & 2 & $1.61(0.40-6.44)$ \\
\hline Kokubo et al ${ }^{26}$ & 89 & 445 & Pro & $\begin{array}{l}\text { Anterior } \\
\text { and posterior }\end{array}$ & 5 & 5 & $1.12(0.47-2.70)$ \\
\hline Vigolo and Mutinelli27 & 39 & 195 & $\mathrm{RCT}$ & Posterior & 5 & 3 & $1.54(0.50-4.77)$ \\
\hline Örtorp et al ${ }^{28}$ & 143 & 715 & Retro & Posterior & 5 & 19 & $2.66(1.69-4.17)$ \\
\hline Passia et al ${ }^{29}$ & 77 & 308 & $\mathrm{RCT}$ & Posterior & 4 & 53 & $17.21(13.15-22.52)$ \\
\hline Reich and Schierz ${ }^{30}$ & 29 & 123 & Pro & Posterior & 4.3 & 1 & $0.81(0.11-5.76)$ \\
\hline Klink and Huettig ${ }^{31}$ & 149 & 596 & Pro & $\begin{array}{l}\text { Anterior } \\
\text { and posterior }\end{array}$ & 4 & 40 & $6.71(4.92-9.15)$ \\
\hline Gherlone et al ${ }^{32}$ & 86 & 241 & Retro & $\begin{array}{l}\text { Anterior } \\
\text { and posterior }\end{array}$ & 2.8 & 26 & $10.80(7.35-15.86)$ \\
\hline Otto and Mörmann ${ }^{33}$ & 61 & 651 & Pro & Posterior & 10.7 & 5 & $0.77(0.32-1.84)$ \\
\hline Baader et al ${ }^{34}$ & 43 & 262 & $\mathrm{RCT}$ & Posterior & 6.1 & 7 & $2.67(1.27-5.60)$ \\
\hline Total summary & 2,916 & 20,503 & $\begin{array}{l}\text { Pro: } 52 \% \\
\text { Retro: } 42 \% \\
\text { RCT: } 5 \%\end{array}$ & $\begin{array}{l}\text { Anterior: } 3 \% \\
\text { Posterior: } 88 \% \\
\text { No information: } \\
9 \%\end{array}$ & 7.0 & 351 & $2.17(1.35-3.51)$ \\
\hline
\end{tabular}

$\mathrm{Cl}=$ confidence interval; Pro = prospective; Retro = retrospective; $\mathrm{RCT}=$ randomized controlled trial.

The International Journal of Periodontics \& Restorative Dentistry

(c) 2018 BY QUINTESSENCE PUBLISHING CO, INC. PRINTING OF THIS DOCUMENT IS RESTRICTED TO PERSONAL USE ONLY. NO PART MAY BE REPRODUCED OR TRANSMITTED IN ANY FORM WITHOUT WRITTEN PERMISSION FROM THE PUBLISHER. 
Table 4 Effects of CAD/CAM System, Restoration Type, Material Type, and Type of Luting Agent on Failures

\begin{tabular}{|c|c|c|c|c|c|c|}
\hline & $\begin{array}{l}\text { Restorations } \\
\text { (n) }\end{array}$ & $\begin{array}{l}\% \text { of all } \\
\text { studies }\end{array}$ & $\begin{array}{l}\text { Mean expo- } \\
\text { sure time }(y)\end{array}$ & $P$ & $\begin{array}{c}\text { Estimated failure rate } \\
\text { (per } 100 \text { restoration y) } \\
(\%[C I])\end{array}$ & $\begin{array}{l}\text { Estimated survival rate } \\
\text { after } 5 \text { years }{ }^{a}(\%[\mathrm{Cl}])\end{array}$ \\
\hline \multicolumn{7}{|c|}{ CAD/CAM system } \\
\hline $\begin{array}{l}\text { CEREC } 1 \\
\text { (Sirona) }\end{array}$ & 1,412 & 21 & 6.8 & .596 & $1.41(0.75-2.63)$ & $93.2(91.2-94.7)$ \\
\hline $\begin{array}{l}\text { CEREC } 2 \\
\text { (Sirona) }^{b}\end{array}$ & 393 & 28 & 5.0 & - & $2.03(1.44-2.86)$ & $90.3(84.9-93.9)$ \\
\hline $\begin{array}{l}\text { CEREC 3/inLab } \\
\text { (Sirona) }\end{array}$ & 502 & 26 & 5.1 & .007 & $2.28(1.17-4.45)$ & $89.2(85.4-92.1)$ \\
\hline $\begin{array}{l}\mathrm{GN}-1 \\
(\mathrm{GC})\end{array}$ & 174 & 7 & 3.9 & .737 & $2.14(0.65-7.01)$ & $89.9(79.6-95.1)$ \\
\hline $\begin{array}{l}\text { Procera } \\
\text { (Nobel Biocare) }\end{array}$ & 237 & 9 & 5.5 & .135 & $2.36(1.65-3.37)$ & $88.9(82.0-93.2)$ \\
\hline $\begin{array}{l}\text { Lava } \\
\text { (3M ESPE) }\end{array}$ & 106 & 5 & 3.9 & $<.001$ & $4.02(0.40-40.02)$ & $81.8(70.7-89.0)$ \\
\hline KaVo ARCTICA & 77 & 3 & 4.0 & $<.001$ & $17.21(13.15-22.52)$ & $42.3(27.3-56.5)$ \\
\hline $\begin{array}{l}\text { Celay } \\
\text { (Mikrona) }\end{array}$ & 15 & 2 & 3.0 & .161 & $6.67(2.15-20.67)$ & $71.6(18.0-93.7)$ \\
\hline \multicolumn{7}{|l|}{ Restoration type } \\
\hline Core crown & 553 & 26 & 3.8 & .092 & $2.63(1.25-5.56)$ & $87.7(83.0-91.2)$ \\
\hline Crown & 360 & 17 & 5.1 & $<.001$ & $2.61(0.99-6.89)$ & $87.8(83.8-90.8)$ \\
\hline Inlay/onlayb & 1,826 & 51 & 5.8 & - & $1.91(1.14-3.21)$ & $90.9(88.8-92.6)$ \\
\hline Endocrown & 120 & 4 & 6.1 & $<.001$ & $2.56(0.62-10.50)$ & $88.0(79.1-93.2)$ \\
\hline Reduced crown & 54 & 2 & 3.8 & .368 & $2.93(1.40-6.14)$ & $86.4(65.2-95.1)$ \\
\hline Veneer & 3 & 1 & 3.0 & .829 & - & - \\
\hline \multicolumn{7}{|l|}{ Material type } \\
\hline $\begin{array}{l}\text { Glass-matrix } \\
\text { ceramic }\end{array}$ & 2,324 & 74 & 5.6 & $<.001$ & $1.79(1.14-2.80)$ & $91.4(89.8-92.8)$ \\
\hline $\begin{array}{l}\text { Polycrystalline } \\
\text { ceramic }^{\mathrm{b}}\end{array}$ & 521 & 22 & 4.1 & - & 4.07 (1.69-9.81) & $81.6(76.7-85.6)$ \\
\hline $\begin{array}{l}\text { Resin-matrix } \\
\text { ceramic }\end{array}$ & 71 & 3 & 2.9 & .046 & $3.85(1.16-12.77)$ & $82.5(59.2-93.2)$ \\
\hline \multicolumn{7}{|l|}{ Luting agent } \\
\hline $\begin{array}{l}\text { Chemically } \\
\text { cured }\end{array}$ & 460 & 22 & 5.0 & $<.001$ & $2.81(0.92-8.62)$ & $86.9(82.6-90.2)$ \\
\hline Light-cured & 654 & 26 & 6.1 & .274 & $1.94(1.13-3.32)$ & $90.8(87.5-93.2)$ \\
\hline Dual-cured ${ }^{b}$ & 1,802 & 52 & 5.4 & - & $2.24(1.17-4.29)$ & $89.4(87.1-91.3)$ \\
\hline Summary & 2,916 & 100 & 7.0 & - & $2.17(1.35-3.51)$ & 89.7 (88.1-91.1) \\
\hline
\end{tabular}

aBased on random effects.

${ }^{b}$ Reference variable.

Among the CAD/CAM systems used, the KaVo ARCTICA system $(P<.001 ; 17.21 \%)$ and the Lava
(3M ESPE) system $(P<.001 ; 4.02 \%)$ showed significantly higher failure rates compared to CEREC 2 (Sirona)
(2.03\%), while the other CAD/CAM systems did not differ significantly (Table 4). 


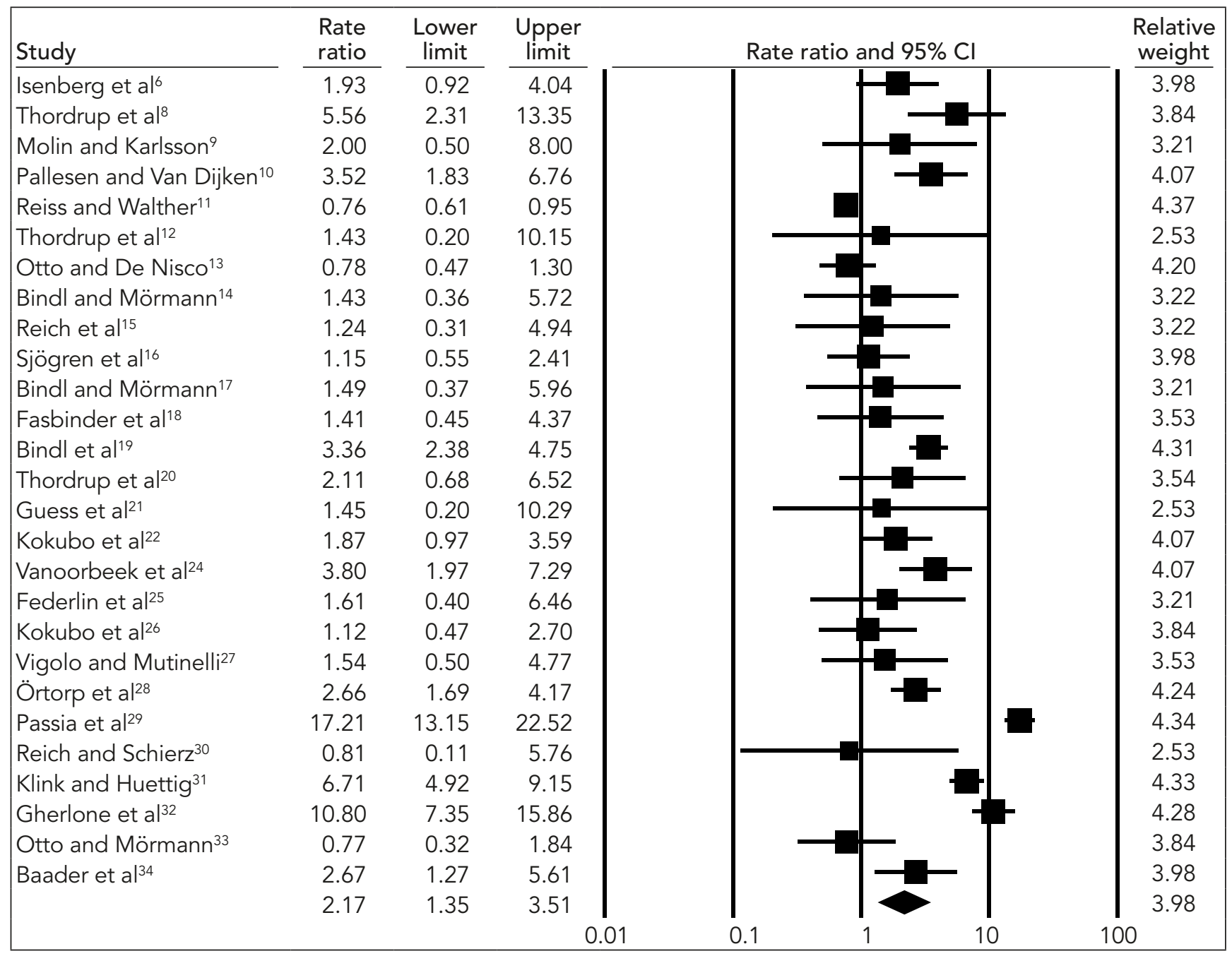

Fig 3 Forest plot: random effects of failure rates, confidence intervals (CI), and weight of each study.

Glass-matrix ceramic restorations exhibited a much lower failure rate than polycrystalline ceramic $(P<.001 ; 1.79 \%$ vs $4.07 \%)$, and resinmatrix ceramic restorations showed significantly higher failure rates compared to polycrystalline ceramic $(P<$ $.046 ; 3.85 \%$ vs $4.07 \%$ ) (Table 4).

Regarding type of restoration, endocrowns $(P<.001 ; 2.56 \%)$ and crowns $(P<.001 ; 2.61 \%)$ revealed a significantly higher failure rate than inlays/onlays (1.91\%), while the other restoration types did not differ significantly. Chemically cured restorations had a higher failure rate when compared to dual-cured restorations ( $P<.001 ; 2.81 \%$ vs $2.24 \%$ ). Outcomes with light-cured restorations were not statistically significant (Table 4).

\section{Discussion}

Despite the advantages of CAD/ CAM technology in fabricating indirect restorations, the driving forces for treatment success are good clinical judgment and skills along with selection of the appropriate material and fabricating process. With any manufacturing process, it is important to respect its various phases for long-term performance objectives.

The introduction of new technologies, manufacturing processes, and materials in dental clinical practice should ideally be supported by scientific evidence. However, literature research reveals the existence of very few well-controlled investigations, such as RCTs, on these issues. ${ }^{35}$

The aim of this investigation was to conduct a systematic review 
of the performance of single-tooth restorations fabricated with CAD/ CAM technology. It also sought to underscore the absence of robust evidence to support the routine use of well-accepted dental restorative treatment protocols.

Specifically, this systematic review evaluated the long-term clinical survival rate of single-tooth restorations fabricated with CAD/CAM technology reported in carefully selected investigations. As expected, only 3 of the 29 studies included are RCTs. This confirms that few studies address this issue with a protocol design covering control groups and random patient selection. This raises concerns regarding clinicians' ability to make evidence-based decisions regarding CAD/CAM restorations. ${ }^{36}$ Other limitations included differences in study design, authors, and the weight of each investigation (Fig 3).

Of the literature included in this systematic review, the research of Reiss and Walther ${ }^{11}$ reporting longterm clinical results of restorations made with the CEREC system presented the greatest scientific relevance (Fig 3). Consequently, the study had an effect on the statistical analysis (weight $=4.37 \%$ ).

Failure analysis in each study was based on different criteria systems: United States Public Health Service criteria (17 studies), California Dental Association criteria (9 studies), and criteria defined by the authors themselves ( 3 studies). In this systematic review, the effect on failure was assessed by the CAD/ CAM system used, the type of restoration, the restoration material, and the luting agent.
The CAD/CAM systems used in the selected studies were CEREC 1 (Sirona), CEREC 2 (Sirona), CEREC 3/inLab (Sirona), GN-1 (GC), Procera (Nobel Biocare), Lava (3M ESPE), KaVo ARCTICA, and Celay (Mikrona). KaVo ARCTICA $(P<.001)$ and Celay $(P<.001)$ had the highest failure rate when compared to the CEREC 2 system. Survival rates after 5 years in function differed: 93.2\% for CEREC 1, 93.0\% for Celay, 90.3\% for CEREC 2, 89.9\% for GN-1, 89.2\% for CEREC 3/inLab, 88.9\% for Procera, $81.8 \%$ for Lava, and $42.3 \%$ for KaVo ARCTICA. The study by Passia et a ${ }^{29}$ was the only article included in this systematic review that used the KaVo ARCTICA system to mill ceramic blocks of $\mathrm{ZrSiO}_{4}$ for the rehabilitation of posterior teeth. They concluded, however, that the use of $\mathrm{ZrSiO} 4$ ceramic crowns in posterior teeth is not recommended. This may be the justification for the high failure rate obtained by the KaVo ARCTICA system.

Regarding the restoration type, crowns $(P<.001 ; 2.61 \%)$ and endo crowns (crowns that extend into the pulp chamber as one piece) ( $P$ $<.001 ; 2.56 \%)$ had a significantly higher failure rate than all other investigated restorations when compared with inlay/onlay restorations. Inlay/onlay restorations had a higher 5-year survival rate (90.9\%), while reduced crowns had the lowest (86.4\%). The survival rates after 5 years for core crown (87.7\%), crown (87.8\%), and endo crown (88.0\%) restorations were quite similar.

According to Land and Hopp ${ }^{37}$ restorations that require less reduction of dental structure, such as in- lays/onlays, present similar clinical results to total covering crowns. In this systematic review, the inlays/onlays (90.9\%; $95 \% \mathrm{Cl}: 88.8 \%$ to $92.6 \%)$ presented a survival rate after 5 years in clinical function superior to the one obtained by total crowns (87.8\%; $95 \% \mathrm{Cl}: 83.8 \%$ to $90.8 \%$ ), suggesting that more conservative dental interventions result in greater clinical performance. Concordant results were obtained by Belli et a ${ }^{38}$ in their study of inlays/onlays and total crown restorations made in IPS e.max CAD blocks (lithium disilicate, Ivoclar Vivadent).

The lowest survival rate was obtained with crowns made on reduced preparations (86.4\%). Similar results were obtained by Bindl et al ${ }^{19}$ that reported survival rates of $92.9 \%$ and $92.1 \%$ for reduced crowns on premolars and molars, respectively, and a survival rate for endocrowns of $68.8 \%$ for premolars and $87.1 \%$ for molars.

The results regarding the type of material showed a low failure rate for glass-matrix ceramics compared to polycrystalline ceramics $(P<.001$; $1.79 \%$ vs $4.07 \%$ ). The highest 5 -year survival rate was obtained by glassmatrix ceramics $(91.4 \%)$, followed by resin-matrix ceramics (82.5\%) and polycrystalline ceramics (81.6\%). The results by type of ceramic showed that resin-matrix ceramics $3.85 \%$; $95 \% \mathrm{Cl}: 1.16 \%$ to $12.77 \%$ ) and polycrystalline ceramics (4.07\%; 95\% $\mathrm{Cl}: 1.69 \%$ to $9.81 \%$ ) had the highest failure rates. Recently, Ankyu et al ${ }^{39}$ concluded in their in vitro study on the fatigue analysis of resin-matrix ceramic crowns that this ceramic material has potential for clinical ap- 
plication in terms of the fatigue resistance parameter.

All failures of polycrystalline ceramic restorations were on posterior teeth and were mostly fabricated in $\mathrm{ZrSiO}_{4}$. The high percentage of $\mathrm{ZrSiO}_{4}$ posterior crowns can, as already mentioned, justify the high failure rate obtained by polycrystalline ceramics.

Belli et al ${ }^{38}$ described a trilayer system, IPS e.max CAD on $\mathrm{ZrO}_{2}$, composed of a machined lithium disilicate overlay (IPS e.max CAD) and a $\mathrm{ZrO}_{2}$ framework, which after being separately sintered are fused together using a fusion glass layer. In their study, they concluded that this system presented significantly better clinical results when compared to monolithic IPS e.max CAD (glass-matrix ceramic) restorations $(P=.0023)$.

Luting agent type evaluation showed that chemically cured restorations had a higher failure rate compared to dual-cured restorations $(P<.001 ; 2.81 \%$ vs $2.24 \%)$.

Dual luting agents have been recommended for ceramic and resin-matrix ceramic inlays to compensate for the obstacle that the restoration itself is to light transmission, and to allow complete polymerization of the luting agent even at the bottom of the cavity, where the access of LED curing light is limited. ${ }^{40}$ Hofmann et $\mathrm{al}_{1}{ }^{40}$ in their comparative study of flexural strength, modulus of elasticity, and surface hardness of several chemically, light-, and dual-curing cements concluded that dual-curing cements produced better mechanical properties than light-curing cements.
Although the present results do not agree with those of Hofmann et al, ${ }^{40}$ the study protocol did not evaluate the polymerization contraction of the different types of cement under different polymerization conditions, or the importance of compliance with the manufacturer's guidelines for selection and use of the different types of cement.

Of 2,916 restorations in clinical function for a mean exposure time of 7.0 years, 351 failures were obtained, leading to an estimated failure rate of $2.17 \%$ per 100 restoration years ( $95 \% \mathrm{Cl}: 1.35 \%$ to $3.51 \%$ ). The overall survival rate after 5 years in clinical function was $87.5 \%(95 \% \mathrm{Cl}$ : $84.5 \%$ to $90.0 \%)$.

Wittneben et al ${ }^{41}$ presented in their systematic review study very similar results: an estimated failure rate of $1.75 \%$ per year (95\% Cl: $1.22 \%$ to $2.52 \%$ ) and an overall survival rate after 5 years in clinical function of $91.6 \%$ (95\% Cl: $88.2 \%$ to $94.1 \%$ ).

In their systematic review on single crowns, Pjetursson et al ${ }^{42}$ reported an overall survival rate after 5 years in clinical function of $93.3 \%$ (95\% Cl: $91.1 \%$ to $95 \%$ ) for ceramic crowns and $95.6 \%(95 \% \mathrm{Cl}: 92.4 \%$ to $97.5 \%)$ for metal-ceramic crowns, which reveals the similarity of the clinical results of crowns produced by CAD/CAM systems when compared with crowns made by conventional techniques.

Boitelle et $\mathrm{a}^{43}$ carried out a systematic review on the fit of restorations made by CAD/CAM systems. They concluded that it is possible to obtain a gap smaller than $80 \mu \mathrm{m}$ between the dental structure and the surface of the CAD/CAM restoration.
This means that CAD/CAM systems achieve values of prosthetic structure adaptation relatively lower than conventional manufacturing methods.

Recently, Morimoto et $\mathrm{al}_{1}{ }^{44}$ in a systematic review of the survival rate of inlays/onlays/overlays, reported a estimated survival rate of $91 \%$ after 10 years in function for glass-ceramics and feldspathic porcelain restorations produced by CAD/CAM technology.

\section{Conclusions}

A lack of studies using a randomization protocol was identified for this particular treatment topic. Nonetheless, the relevant and selected literature reveals an overall survival rate of $87.5 \%$ after 5 years $(95 \% \mathrm{Cl}$ : $84.5 \%$ to $90.0 \%$ ) and an estimated failure rate of $2.17 \%$ ( $95 \% \mathrm{Cl}: 1.35 \%$ to $3.51 \%$ ). Additional findings include the following: (1) KaVo ARCTICA $(P<.001 ; 17.21 \%)$ and Lava $(P<.001 ; 4.02 \%)$ had a higher failure rate when compared to CEREC 2 (2.03\%); (2) glass-matrix ceramic restorations $(P<.001 ; 1.79 \%)$ and resin-matrix restorations $(P=.046$; $3.85 \%)$ showed a lower failure rate when compared to polycrystalline ceramic restorations (4.07\%); (3) fullcoverage crowns $(P<.001 ; 2.61 \%)$ and endo crowns ( $P=.001 ; 2.56 \%)$ showed a higher failure rate when compared to inlay/onlay restorations (1.91\%); and (4) chemically cured restorations $(P<.001 ; 2.81 \%)$ showed a higher failure rate when compared to dual-cured restorations (2.24\%). 


\section{Acknowledgments}

The authors received no financial support and reported no conflicts of interest related to this study.

\section{References}

1. Miyazaki T, Hotta Y, Kunii J, Kuriyama S, Tamaki Y. A review of dental CAD/CAM: Current status and future perspectives from 20 years of experience. Dent Mater J 2009;28:44-56.

2. Fernandez IM, Mogollones RF, Castilla MV. Flexural resistance of esthetic materials used by indirect restoration. A comparative in vitro study. Int J Odontostomat 2013;7:315-318.

3. Witkowski S. (CAD-)/CAM in dental technology. Quintessence Dent Technol 2005;28:169-184.

4. Moher D, Liberati A, Tetzlaff J, Altman DG, PRISMA Group. Preferred reporting items for systematic reviews and metaanalyses: The PRISMA statement. Ann Intern Med 2009;151:264-269.

5. Schardt C, Adams MB, Owens T, Keitz S, Fontelo P. Utilization of the PICO framework to improve searching PubMed for clinical questions. BMC Med Inform Decis Mak 2007;7:16.

6. Isenberg $B P$, Essig ME, Leinfelder KF. Three-year clinical evaluation of CAD/ CAM restorations. J Esthet Dent 1992; 4:173-176.

7. Heymann HO, Bayne SC, Sturdevant JR, Wilder AD Jr, Roberson TM. The clinical performance of CAD-CAM-generated ceramic inlays: A four-year study. J Am Dent Assoc 1996;127:1171-1181.

8. Thordrup M, Isidor F, Hörsted-Bindslev P. A 3-year study of inlays milled from machinable ceramic blocks representing 2 different inlay systems. Quintessence Int 1999:30:829-836.

9. Molin MK, Karlsson SL. A randomized 5 -year clinical evaluation of 3 ceramic inlay systems. Int J Prosthodont 2000;13: 194-200.

10. Pallesen U, van Dijken JW. An 8-year evaluation of sintered ceramic and glass ceramic inlays processed by the Cerec CAD/CAM system. Eur J Oral Sci 2000; 108:239-246.

11. Reiss B, Walther W. Clinical long-term results and 10-year Kaplan-Meier analysis of Cerec Restorations. Int J Comput Dent 2000;3:9-23.
12. Thordrup $M$, Isidor F, Hörsted-Bindslev P. A 5-year clinical study of indirect and direct resin composite and ceramic inlays. Quintessence Int 2001;32:199-205.

13. Otto T, De Nisco S. Computer-aided direct ceramic restorations: $A$ 10-year prospective clinical study of Cerec CAD/ CAM inlays and onlays. Int J Prosthodont 2002;15:122-128.

14. Bindl A, Mörmann WH. An up to 5-year clinical evaluation of posterior in-ceram CAD/CAM core crowns. Int J Prosthodont 2002;15:451-456.

15. Reich SM, Wichmann $M$, Rinne $H$, Shortall A. Clinical performance of large, all-ceramic CAD/CAM-generated restorations after three years: A pilot study. J Am Dent Assoc 2004;135:605-612.

16. Sjögren G, Molin M, van Dijken JW. A 10-year prospective evaluation of CAD/ CAM-manufactured (Cerec) ceramic inlays cemented with a chemically cured or dual-cured resin composite. Int J Prosthodont 2004;17:241-246.

17. Bindl A, Mörmann WH. Survival rate of mono-ceramic and ceramic-core CAD/ CAM-generated anterior crowns over 2-5 years. Eur J Oral Sci 2004;112:197-204.

18. Fasbinder DJ, Dennison JB, Heys DR, Lampe K. The clinical performance of CAD/CAM-generated composite inlays. J Am Dent Assoc 2005;136:1714-1723.

19. Bindl A, Richter $B$, Mörmann WH. Survival of ceramic computer-aided design/ manufacturing crowns bonded to preparations with reduced macroretention geometry. Int J Prosthodont 2005;18: 219-224.

20. Thordrup $M$, Isidor F, Hörsted-Bindslev P. A prospective clinical study of indirect and direct composite and ceramic inlays: Ten-year results. Quintessence Int 2006; 37:139-144.

21. Guess PC, Strub JR, Steinhart N, Wolkewitz M, Stappert CF. All-ceramic partial coverage restorations-Midterm results of a 5-year prospective clinical splitmouth study. J Dent 2009;37:627-637.

22. Kokubo Y, Sakurai S, Tsumita M, Ogawa T, Fukushima S. Clinical evaluation of Procera AllCeram crowns in Japanese patients: Results after 5 years. J Oral Rehabil 2009;36:786-791.

23. Beuer F, Stimmelmayr M, Gernet W, Edelhoff D, Güh JF, Naumann M. Prospective study of zirconia-based restorations: 3-year clinical results. Quintessence Int 2010;41:631-637.
24. Vanoorbeek S, Vandamme K, Lijnen I, Naert I. Computer-aided designed/ computer-assisted manufactured composite resin versus ceramic single-tooth restorations : A 3-year clinical study. Int J Prosthodont 2010;23:223-230.

25. Federlin M, Hiller KA, Schmalz G. Controlled, prospective clinical split-mouth study of cast gold vs ceramic partial crowns: 5.5 year results. Am J Dent 2010; 23:161-167.

26. Kokubo Y, Tsumita M, Sakurai S, Suzuki Y, Tokiniwa Y, Fukushima S. Five-year clinical evaluation of In-Ceram crowns fabricated using GN-I (CAD/CAM) system. J Oral Rehabil 2011;38:601-607.

27. Vigolo $P$, Mutinelli $S$. Evaluation of zirconium-oxide-based ceramic singleunit posterior fixed dental prostheses (FDPs) generated with two CAD/CAM systems compared to porcelain-fusedto-metal single-unit posterior FDPs: A 5-year clinical prospective study. J Prosthodont 2012;21:265-269.

28. Örtorp A, Kihl ML, Carlsson GE. A 5-year retrospective study of survival of zirconia single crowns fitted in a private clinical setting. J Dent 2012;40:527-530.

29. Passia N, Stampf S, Strub JR. Five-year results of a prospective randomised controlled clinical trial of posterior computer-aided design-computeraided manufacturing $\mathrm{ZrSiO} 4$-ceramic crowns. J Oral Rehabil 2013;40:609-617.

30. Reich S, Schierz O. Chair-side generated posterior lithium disilicate crowns after 4 years. Clin Oral Investig 2013;17: 1765-1772.

31. Klink A, Huettig F. Complication and survival of Mark II restorations: 4-year clinical follow-up. Int J Prosthodont 2013; 26:272-276.

32. Gherlone E, Mandelli F, Capparè $P$, Pantaleo G, Traini T, Ferrini F. A 3 years retrospective study of survival for zirconia-based single crowns fabricated from intraoral digital impressions. J Dent 2014;42:1151-1155.

33. Otto T, Mörmann WH. Clinical performance of chairside CAD/CAM feldspathic ceramic posterior shoulder crowns and endocrowns up to 12 years. Int J Comput Dent 2015;18:147-161.

34. Baader K, Hiller KA, Buchalla W, Schmalz G, Federlin M. Self-adhesive luting of partial ceramic crowns: Selective enamel etching leads to higher survival after 6.5 years in vivo. J Adhes Dent 2016; 18:69-79. 
35. Pjetursson BE, Lang NP. Prosthetic treatment planning on the basis of scientific evidence. J Oral Rehabil 2008;35(Suppl 1): 72-79.

36. Kelly JR. Developing meaningful systematic review of CAD/CAM reconstructions and fiber-reinforced composites. Clin Oral Implants Res 2007;18(Suppl 3): 205-217.

37. Land MF, Hopp CD. Survival rates of all-ceramic systems differ by clinical indication and fabrication method. J Evid Based Dent Pract 2010;10:37-38.

38. Belli R, Petschelt A, Hofner B, Hajtó J, Scherrer SS, Lohbauer U. Fracture rates and lifetime estimations of CAD/CAM all-ceramic restorations. J Dent Res 2016; 95:67-73.
39. Ankyu S, Nakamura K, Harada A, et al. Fatigue analysis of computer-aided design/computer-aided manufacturing resin-based composite vs lithium disilicate glass-ceramic. Eur J Oral Sci 2016;124: 387-395.

40. Hofmann N, Papsthart G, Hugo B, Klaiber B. Comparison of photo-activation versus chemical or dual-curing of resin-based luting cements regarding flexural strength, modulus and surface hardness. J Oral Rehabil 2001;28: 1022-1028.

41. Wittneben JG, Wright RF, Weber HP, Gallucci GO. A systematic review of the clinical performance of CAD/CAM single-tooth restorations. Int J Prosthodont 2009;22:466-471.
42. Pjetursson BE, Sailer I, Zwahlen M, Hämmerle $\mathrm{CH}$. A systematic review of the survival and complication rates of all-ceramic and metal-ceramic reconstructions after an observation period of at least 3 years. Part I: Single crowns. Clin Oral Implants Res 2007;18(Suppl 3):73-85.

43. Boitelle P, Mawussi $B$, Tapie L, Fromentin O. A systematic review of CAD/CAM fit restoration evaluations. J Oral Rehabil 2014;41:853-874.

44. Morimoto S, Rebello de Sampaio FB, Braga MM, Sesma N, Özcan M. Survival rate of resin and ceramic inlays, onlays, and overlays: A systematic review and meta-analysis. J Dent Res 2016;95: 985-994. 